
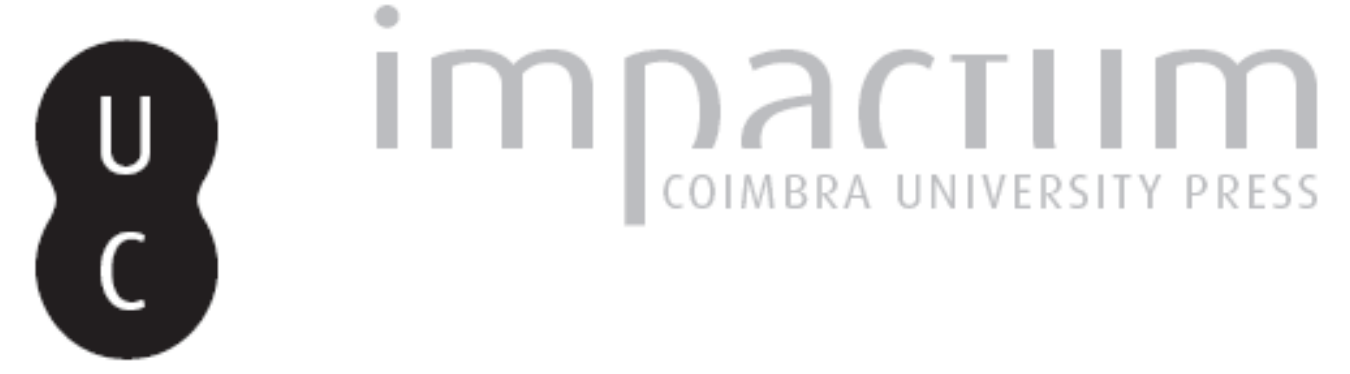

\title{
[Recensão a] Comentário da obra de Adrian Goldsworthy, Generais Romanos. Os homens que construíram o Império Romano
}

Autor(es): $\quad$ Monteiro, João Gouveia

Publicado por: Centro de História da Sociedade e da Cultura

URL persistente:

URI:http://hdl.handle.net/10316.2/39678

DOI:

DOI:http://dx.doi.org/10.14195/1645-2259_8_11

Accessed : $\quad$ 26-Apr-2023 10:46:39

A navegação consulta e descarregamento dos títulos inseridos nas Bibliotecas Digitais UC Digitalis, UC Pombalina e UC Impactum, pressupõem a aceitação plena e sem reservas dos Termos e Condições de Uso destas Bibliotecas Digitais, disponíveis em https://digitalis.uc.pt/pt-pt/termos.

Conforme exposto nos referidos Termos e Condições de Uso, o descarregamento de títulos de acesso restrito requer uma licença válida de autorização devendo o utilizador aceder ao(s) documento(s) a partir de um endereço de IP da instituição detentora da supramencionada licença.

Ao utilizador é apenas permitido o descarregamento para uso pessoal, pelo que o emprego do(s) título(s) descarregado(s) para outro fim, designadamente comercial, carece de autorização do respetivo autor ou editor da obra.

Na medida em que todas as obras da UC Digitalis se encontram protegidas pelo Código do Direito de Autor e Direitos Conexos e demais legislação aplicável, toda a cópia, parcial ou total, deste documento, nos casos em que é legalmente admitida, deverá conter ou fazer-se acompanhar por este aviso.

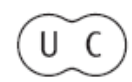




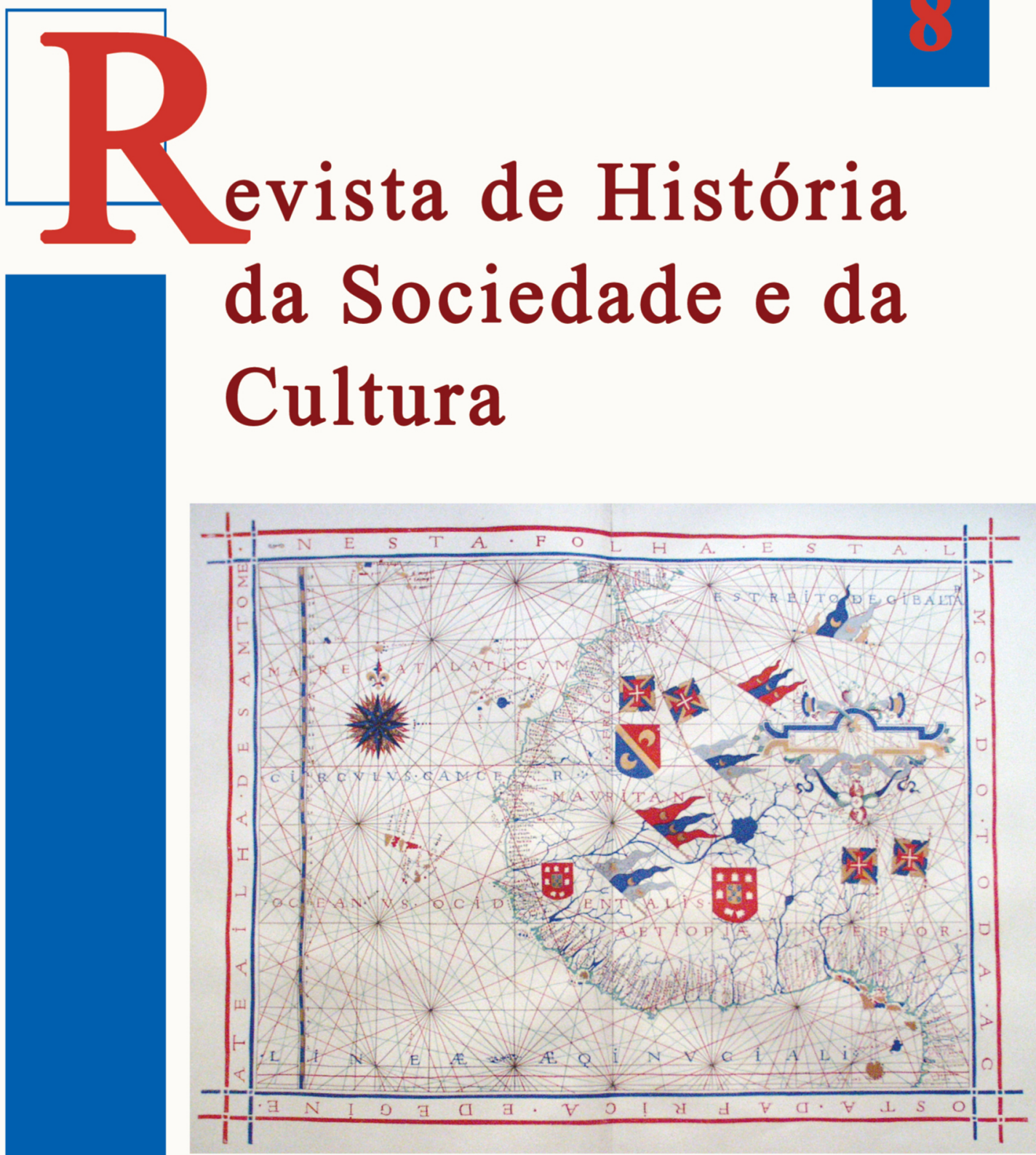

Centro de História da Sociedade e da Cultura Universidade de Coimbra

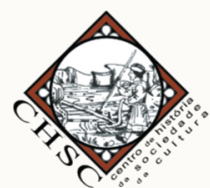


raser les fossés des glacis (pour empêcher les assiégeants de s'y abriter). Ils essayèrent de tenir jusqu'au 11 mars 1769, jour où, comme on l'a dit, ils s'embarquèrent dans des navires portugais qui les emmenèrent à Lisbonne. Les assiégés, en voyant arriver l'armada, crurent que c'était le secours qu'ils attendaient, mais avec elle venait l'ordre de livrer la place et de s'embarquer pour le Portugal. Après un moment de révolte, les défenseurs obéirent et, la nuit venue, montèrent dans les bateaux.

Et qu'avait donc prévu le Gouvernement de Lisbonne, présidé par le puissant Marquis de Pombal? D'employer les 2100 personnes qui résistaient dans la forteresse de Mazagan à aider au peuplement de l'Amazonie. Mazagan, en effet, ne représentait plus grand-chose pour les Portugais, tandis que sa signification était grande pour les Marocains. N'était-ce pas leur terre, leur patrie? Des sources historiques nous disent cependant que, forcés de quitter Mazagan, certains Portugais moururent de regret, ou, pour employer un mot très portugais, de «saudade».

\section{João Marinho dos Santos}

\section{Comentário da obra de Adrian Goldsworthy, Generais Romanos.} Os homens que construíram o Império Romano (trad. port. de Carlos Fabião, Lisboa, A Esfera dos Livros, 2007, 543 pp.; ed. orig.: 2003)

Dando seguimento a uma série de boas novidades editoriais, algumas delas com incidência na história militar da Antiguidade (vide o belo livro de Maurício Pastor Muñoz, Viriato, Prefácio e adaptação à edição portuguesa de José d'Encarnação, 2006), a editora A Esfera dos Livros ofereceu-nos, em Outubro de 2007, a obra de Adrian Golsdworthy intitulada Generais Romanos. Os homens que construíram o Império Romano.

O autor, apesar de ainda relativamente jovem (nasceu em 1969) já é, hoje em dia, um dos especialistas de história militar de Roma mais citados em todo o Mundo. De nacionalidade inglesa, Adrian Goldsworthy licenciou-se em Oxford e aí se doutorou também, com a tese The Roman Army at War, $100 B C-A D$ 200. Este trabalho, publicado pela primeira vez em 1996 na prestigiada colecção Oxford Classical Monographs (destinada a dar à 
estampa as melhores teses apresentadas nas áreas de Literatura Grega e Latina, de História Antiga e de Filosofia Antiga, sob supervisão do Faculty Board of Literae Humaniores) configurou um estudo extremamente inovador sobre o exército romano, desafiando mesmo algumas 'vacas sagradas' do entendimento tradicional sobre a forma como as legiões romanas eram organizadas e distribuídas no terreno e sobre a natureza dos segredos tácticos que fizeram da máquina de guerra romana o maior e melhor exército do Mundo do seu tempo. Posteriormente, Adrian Goldsworthy manteve-se fiel a esta irreverência historiográfica, algo inspirada nos modelos humanizantes de John Keegan (que, em 1976, abalara o mundo dos historiadores militares com a publicação do livro The Face of Battle - trad. port.: O Rosto da Batalha, Lisboa, Fragmentos, 1987), oferecendo-nos outros trabalhos de muito interesse sobre o exército romano, sobre a sua maneira muito própria de pensar e de fazer a guerra (ex: Roman Warfare, Phoenix 2000), sobre as suas grandes guerras e batalhas (exs: The Punic Wars, ou Cannae, ambos da Cassell, 2001) ou sobre os seus grandes heróis (ex: Caesar: Life of a Colossus, Yale University Press, 2006). O sucesso editorial destes livros levou mesmo Goldsworthy, que chegou a ser investigador da Universidade de Cardiff, a dedicar-se preferencialmente à escrita, sem prejuízo de também dar aulas na Universidade de Notre Dame, em Londres.

Quanto à obra em apreço, Generais Romanos, convém começar por lembrar que se trata de uma tradução portuguesa, assinada por Carlos Fabião (arqueólogo e professor da Faculdade de Letras da Universidade de Lisboa), de um livro datado de 2003. Um livro grande (543 pp. na sua edição portuguesa) e, podemos desde já dizê-lo, um grande livro também. Tivemos o gosto de o ler integralmente e, por felicidade, graças a um aviso prudente da nossa querida colega e amiga Doutora Raquel Vilaça, pudemos igualmente assistir a uma espécie de pré-lançamento da obra, concretizado na Faculdade de Letras de Lisboa em 16 de Outubro de 2007 através de uma palestra de Adrian Goldsworthy sobre o tema genérico "As vitórias e conquistas do exército romano", em boa hora promovida pelo Centro de História e pelo Centro de Arqueologia da Universidade de Lisboa, em jeito de aproveitamento da presença do autor em Portugal para o lançamento da edição portuguesa do seu livro. Tanto num momento como noutro (acompanhamento da palestra e posterior leitura da obra) pudemos constatar 
a grande qualidade do conferencista e autor, o seu enorme conhecimento da temática da guerra na Roma antiga e a sua originalidade e criatividade na abordagem dos temas mais complexos.

Generais Romanos. Os homens que construíram o Império Romano é uma obra composta por: i) uma Nota Prévia do tradutor (sóbria e chamando muito pertinentemente a atenção para um dos principais méritos deste livro: o de conseguir "um belíssimo e equilibrado balanço entre divulgação e erudição" - p. III); ii) um Prefácio do autor (recordando o seu percurso no Corpo de Treino de Oficiais de Oxford, "o único lugar onde se pode aprender a liderar", e adiantando que os generais romanos não recebiam treino formal antes de serem nomeados, sendo escolhidos mais pelas suas ligações familiares e políticas - ou seja, eram "amadores", o que não significa que não fossem bons); iii) uma Introdução, longa de 20 páginas e, como veremos, importantíssima para o acompanhamento do livro; iv) quinze capítulos sobre outros tantos grandes generais romanos, situados cronologicamente entre 275 a.C. e 565 d.C., i.e. cobrindo um arco temporal de quase oito séculos e meio); v) um capítulo de encerramento, versando "o legado dos generais romanos" até aos dias de hoje; vi) por fim, três anexos muito úteis (Cronologia, Glossário e Índice Remissivo). A obra, com boa qualidade de impressão, mancha agradável e manuseamento muito confortável, apesar da sua dimensão, inclui ainda 15 ilustrações a preto e branco, entre mapas e esquemas. Acrescentaremos que a tradução de Carlos Fabião é de muito boa qualidade, o que, nos tempos que correm, constitui uma verdadeira bênção para o leitor português, saturado que está de versões apressadas ou abrasileiradas de obras de manifesto interesse científico ou pedagógico.

Na sua Introdução (intitulada "No início: de chefe e herói a político e general", pp. 15-35), Adrian Goldsworthy explica sobretudo como os Romanos, que eram tão hábeis a copiar dos seus inimigos as armas e tácticas que mais os impressionavam, fizeram questão de conservar uma originalidade muito própria ao nível da estrutura interna do seu exército e das funções atribuídas aos respectivos comandantes. Os generais pertenciam às camadas aristocráticas, pois os Romanos acreditavam que só eles poderiam servir adequadamente a República. E a sua aprendizagem fazia-se sobretudo através da observação dos outros e da experiência pessoal (Academias Militares foi 
algo que nunca existiu em Roma). Ao contrário do que muitas vezes se pensa (vide, p.ex., as teses de J. F. C. Fuller ou de W. Messer), o sistema táctico das legiões não foi desenhado para transferir responsabilidades dos generais para os oficiais subalternos (em especial para os centuriões). Pelo contrário, o papel do general era valorizado, consistindo a sua primeira função, não tanto em "mergulhar na refrega, de espada ou lança na mão, lutando à cabeça dos seus homens, partilhando os seus riscos" (p. 15), mas mais em dirigir o combate, movimentando-se pelas linhas recuadas, observando os movimentos nas diversas zonas do terreno, retendo ou fazendo avançar as reservas, em síntese, garantindo a correcta utilização de todos os recursos disponíveis com vista à vitória final. Para tal, não era apenas necessário um bom conhecimento das tácticas, mas também capacidade para dirigir os homens e para entender as suas motivações e sentimentos mais profundos (eis um ponto em que Goldsworthy se aproxima muito do 'rosto da batalha' proposto por John Keegan).

Nesta Introdução, Goldsworthy salienta ainda as limitações das fontes em que se baseia para a construção da sua obra: essencialmente fontes literárias (o que tem sido uma condicionante por vezes apontada aos trabalhos deste autor, sobretudo por aqueles que tendem a valorizar cada vez mais os contributos da Arqueologia, da Epigrafia ou até da Papirologia), com privilégio dos testemunhos directos (sobretudo Políbio, Júlio César, Flávio Josefo, Amiano Marcelino e Procópio). No entanto, Goldsworthy também reconhece as limitações destas fontes e tem perfeita noção da necessidade de as utilizar de maneira crítica. O autor lamenta ainda a circunstância de apenas dispormos de verdadeiras histórias de Roma a partir do final da Segunda Guerra Púnica (201 a.C.) e, sobretudo, empenha-se em justificar a transformação do exército romano desde os primórdios da República até à afirmação de Roma na Península Itálica (e mesmo fora dela), convocando para tal o seu bom conhecimento das tradições militares grega (vide a falange hoplita) e helenística para explicar de forma didáctica ao seu leitor uma tal evolução. Um outro ponto essencial consiste na explicitação do carácter simultaneamente político e militar da carreira dos generais romanos (cônsules que perfaziam um longo cursus honorum, até obterem um comando militar por escassos 12 meses e que, em princípio, não poderiam repetir antes de completado um intervalo de 10 anos). 
Esta Introdução remata com uma indicação muito clara e muito pedagógica da composição e distribuição da legião romana no campo de batalha entre finais do séc. IV a.C. e o séc. II a.C. (acompanhada, na p. 32, por um esquema muito útil alusivo ao chamado "exército manipular"), completada por algumas reflexões acerca da evolução do recrutamento militar durante os primeiros séculos da República e de uma síntese dos factores que mais condicionavam a actuação dos generais coevos (escassa velocidade de circulação da informação, ausência de mapas e limitações do armamento). Condicionalismos esses que, paradoxalmente, acabavam por valorizar o papel do general como elemento de coordenação imprescindível, convidando a uma chefia directa e pessoal das operações, conquanto já não tão 'exposta' e imprudente (salvo em casos de débâcle iminente) como em épocas mais primitivas ou mesmo nos termos do modelo protagonizado por Alexandre Magno.

Seguem-se os 15 capítulos centrados nas figuras de outros tantos generais. A escolha de Goldsworthy recaiu sobre os seguintes personagens: Fábio Máximo (275-203 a.C., um adversário difícil e astuto de Aníbal Barca) e Marco Cláudio Marcelo (271-208 a.C., um herói à moda antiga, que virou a página humilhante de Canas e tomou Siracusa): Capítulo 1 (pp. 37-56); Cipião Africano (236-184 a.C., o lendário vencedor da Segunda Guerra Púnica, vitorioso na batalha de Zama): Capítulo 2 (pp. 57-87); Emílio Paulo (228-160 a.C., o conquistador da Macedónia, triunfador em Pidna): Capítulo 3 (pp. 89-122); Cipião Emiliano (185/4-129 a.C., o conquistador de Numância): Capítulo 4 (pp. 123-142); Caio Mário (157-86 a.C., cônsul sete vezes, vencedor de Jugurta e dos Cimbros e Teutões): Capítulo 5 (pp. 143-172); Sertório (125-72 a.C., um general rebelde no exílio da Hispânia durante a ditadura de Sula): Capítulo 6 (pp. 173-190); Pompeio o Magno (106-48 a.C., um "Alexandre romano", vencedor na Hispânia, contra Sertório, decisivo na guerra contra Mitridates, rei do Ponto, e exterminador dos piratas do Mediterrâneo): Capítulo 7 (pp. 191-226); Júlio César (100-44 a.C., triunfante na Gália, invasor da Britânia, vencedor de Pompeio na guerra civil de 49-45 a.C.): Capítulos 8 e 9 (pp. 227-298); Germânico (15 a.C.-19 d.C., um príncipe precocemente desaparecido, conquistador na Germânia de além-Reno): Capítulo 10 (pp. 299-331); Córbulo (forçado pelas desconfianças de Nero ao suicídio, em 67 d.C., deixou a sua marca na Germânia e, sobretudo, 
na montanhosa Arménia): Capítulo 11 (pp. 333-366); Tito (41-81 d.C., o jovem general que tomou Jerusalém para o pai, o imperador Vespasiano): Capítulo 12 (pp. 367-398); Trajano (56-117 d.C., o imperador que conquistou a Dácia, na actual Roménia): Capítulo 13 (pp. 399-423); Juliano (332-363 d.C., um aclamado César na Gália, um efémero e infeliz Augusto na Pérsia): Capítulo 14 (pp. 425-454); e Belisário (505-565 d.C., um general bizantino ao serviço de Justiniano, na Pérsia): Capítulo 15 (pp. 455-488).

Claro que esta escolha suscita alguns comentários. Em primeiro lugar, parece-nos que os comandantes seleccionados são de facto, todos eles, exemplos de generais com valor (mesmo Juliano, apesar das reticências do próprio Goldsworthy a este respeito: p. 16). Alguns desses homens (p.ex. Cipião Africano, Cipião Emiliano, Mário, um novus homo, César ou até o metódico Pompeio) contam-se mesmo entre os grandes generais que o Ocidente conheceu ao longo da Antiguidade. Nesse sentido, a escolha de Goldsworthy é lógica e não parece deixar de fora ninguém verdadeiramente merecedor de ombrear com os eleitos. A questão que se pode colocar (e que o próprio autor assume: p. 16) é a do desequilíbrio cronológico desta selecção. Se a ideia era, como o título da obra (pelo menos na sua versão portuguesa) indica, destacar os grandes comandantes que "construíram o Império Romano", então há que lamentar que, para os séculos II a VI d.C., só tenhamos o exemplo de três grandes generais (Trajano, Juliano e Belisário), o último dos quais com um enquadramento político claramente distinto, proporcionado pela sua inserção no Império Bizantino (o Império Romano, sim, mas do Oriente). A que devemos então esta lacuna, que faz com que entre a morte de Trajano durante a sua campanha na Arábia (em 117 d.C.) e a nomeação de Juliano como César do seu tio Constâncio II para o governo do Ocidente (em 355 d.C.), ou seja, ao longo de quase dois séculos e meio, não encontremos neste belo livro qualquer exemplo de um grande general romano?

Em primeiro lugar, trata-se de um problema de fontes. Para a época em questão (117-355 d.C.) já não temos Lívio (n. 59 a.C.), nem Josefo (n. c.37 d.C.), nem Plutarco (n. c.46 d.C.), nem Tácito (n. c. 56 d.C.), nem Suetónio (n. c.69 d.C.), nem Apiano (n. c.95 d.C.), muito menos os velhos Políbio (m. c. 120 a.C.), César (m. 44 a.C.) ou Salústio (m. 34 a.C.). E, por outro lado, não temos ainda Amiano Marcelino (c. 330-c.395 d.C.), nem Procópio 
(meados do séc. VI d.C.). Restam-nos Díon Cássio (c.163-c.235 d.C., cuja obra se perdeu em grande parte), Herodiano (m. c.250 d.C., muitas vezes vago e pouco fiável) e pouco mais, p.ex., algumas fontes cristãs (como Tertuliano: c.150-c.225 d.C.) ou administrativas (como João-o-Lídio, 2. ${ }^{a}$ metade do séc. III - inícios do séc. IV d.C.). Escasso material, portanto, para Adrian Goldsworthy conseguir equilibrar a sua escolha. Dir-se-á que era altura de fazer intervir outro tipo de fontes - arqueológicas, epigráficas, artísticas. Não nos parece, todavia, que tal fosse exequível numa obra que, assumidamente, visa sobretudo reconstituir a evolução das formas de comando e a relação dos generais com os seus homens, nos teatros de guerra. Neste particular, as fontes não literárias, sendo preciosas, ajudam pouco. Como, caricaturando bastante, Goldsworthy afirmou na palestra de Lisboa, a Arqueologia é muito útil, mas ... quanto tempo por dia é que nós passamos com um prato de comer nas mãos?...

Há, entretanto, uma outra explicação para o vazio de 117 a 355. Em nossa opinião, a ausência de grandes generais conhecidos também tem que ver com as características da guerra nesse período. Com Trajano (justamente o imperador que morre em 117), o Império Romano alcança praticamente a sua máxima extensão. A partir de então, trata-se essencialmente de garantir a integridade desse imenso mosaico de territórios e de povos, à mistura com algumas campanhas para além desses limites (p.ex. a Oriente) mas que são, tantas vezes, mais factores de pressão sobre os 'bárbaros' mais próximos da fronteira, ou sobre os agressivos Persas, do que propriamente intenções assumidas de incorporação duradoura de novos territórios no mundo romano. Ou então essas campanhas são decisões pontuais de alguns imperadores, sonhos pessoais que os seus sucessores rapidamente desmontam, tal como fez Adriano com as conquistas orientais de Trajano, assim que assumiu o poder em 117. Neste enquadramento, a luta era mais uma guerra de raids, de incursões de fronteira, de defesa de posições. Intensa, sim, mas menos propícia a grandes destaques individuais. Os próprios imperadores se viram por vezes forçados a participar activamente nela, permanecendo largos anos nas proximidades do limes, em vez de entregarem a sorte das campanhas a grandes generais. Não terá sido por acaso que Ridley Scott, ao realizar o belo filme Gladiador (2000), começou justamente por mostrar o imperador Marco Aurélio (161-180 d.C.) acompanhando de perto essa guerra de desgaste e 
usura contra Germanos ou Sarmatas! Aliás, se quisermos apontar grandes batalhas ocorridas durante o período 117-355 d.C. temos muita dificuldade, e as poucas que conseguiremos citar correspondem precisamente, et pour cause, a confrontos ocorridos nas guerras civis (exs: Ponte Mílvia, em 312, combate entre Constantino e o seu rival Maxêncio; ou Crisópolis, uma batalha naval entre Constantino e Licínio).

Mas há mais, e bem a propósito: entre 117 e 355 sobreveio também a famosa crise do século III. Com ela, a máquina militar romana perdeu coesão e eficácia. Assistiu-se a uma tremenda erosão da autoridade dos generais e, sobretudo no período compreendido entre o assassinato de Cómodo, em 192 (que encerrou tragicamente a distintíssima dinastia dos Antoninos), e a renovação do regime político com Diocleciano (284-305) e Constantino I (312/24-337) seria praticamente impossível encontrar comandantes militares com condições objectivas, i.e. com meios humanos e com apoios políticos e técnicos suficientemente expressivos e estáveis para se afirmarem como grandes generais, pelo menos em moldes semelhantes aos dos antecessores de Trajano.

Assim sendo, compreendemos as dificuldades e aceitamos o resultado final da escolha de Goldsworthy. Quanto ao desenvolvimento de cada capítulo diremos que, ainda que inevitavelmente desigual (até em resultado das fontes disponíveis), ele é, em média, excelente. Não esconde uma certa predilecção por Júlio César (de quem alguns autores dizem, talvez com malícia, ter sido mais um magnífico condutor de homens do que um bom estratego militar, salvando-se não poucas vezes graças aos prodígios da engenharia romana), mas, no geral, é bastante equilibrado e informativo. O leitor encontrará belas e detalhadas descrições de grandes operações militares, como por exemplo a tomada de Nova Cartago, na Hispânia (por Cipião Africano, em 209 a.C.); ou a batalha de Ilipa, três anos mais tarde (em que o génio táctico do mesmo Cipião desconcerta por completo Asdrúbal Giscão e liquida as ambições cartaginesas na Península Ibérica); ou a batalha de Pidna, em 168 a.C. (um combate em que um animal perdido provoca o início acidental da batalha e onde o cônsul Emílio Paulo praticamente assegura a vitória de Roma na terceira e última das Guerras Macedónicas); ou o lendário cerco de Alésia por Júlio César, em 52 a.C., em que os Romanos constróem “uma linha de fortificações de cerca de $17 \mathrm{~km}$ de extensão, com vinte e três fortes 
ligados por fosso e muralha de terra", e, mais tarde, prevenindo a chegada de um exército de socorro a Vercingetorige, erguem "uma nova linha de contravalação (i.e., fortificação voltada ao exterior) praticamente análoga" - p. 262); ou o terrível cerco de Jerusalém, em 70 d.C. (onde os Romanos se servem de fortes aríetes para romper as muralhas e de poderosa artilharia que arremessava pedras com $26 \mathrm{~kg}$ de peso a dois estádios - quase 400 metros de distância, segundo a narrativa de Flávio Josefo, um ex-general judaico mas que, tendo mudado de partido, assistia agora ao assédio no interior do quartel-general de Tito); ou ainda, e para citar um último exemplo de uma geografia e cronologia distintas, a batalha de Dara, em 530 d.C. (uma grande vitória de Belisário sobre os Persas). Acresce que todos os eventos que citámos são apoiados por mapas ou esquemas de grande utilidade e, em geral, de muito fácil leitura. A este propósito, lamentamos apenas que tais imagens não tenham tido uma última revisão, um pouco mais cuidada e uniformizadora, pois existem diversos exemplos de topónimos cuja grafia é diversa no texto e no mapa/esquema. Por exemplo, no mapa da p. 221 encontramos "Cólquida", enquanto no texto da p. 220 se pode ler "Cólquidia"; da mesma maneira, no mapa da p. 325, "Idistaviso" não bate certo com a forma "Idisiaviso" que se acha no texto da p. 327. Um outro exemplo de uma falha menor ao nível da ilustração (que em geral, repetimos, é bastante boa) parece ser fornecido pelo mapa da p. 403, o qual tem como legenda geral "O Império de Trajano" (cujo Principado já vimos ter decorrido entre 98 e 117 d.C.), mas apresenta depois, enquadrando a legenda, o título "O Império Romano em 214 d.C.".

Porém, nem esses desacertos nem outros pequenos pormenores que, por preciosismo, poderíamos aqui discutir (como, p.ex., a referência, na p. 132, ao pranto de Cipião por alturas da destruição de Cartago, em que se diz que o grande general "chorou e citou um passo da Ilíada, narrando a destruição de Tróia" - de facto, na Ilíada, estamos ainda muito longe da destruição de Tróia, que só aí poderia figurar de forma premonitória) retiram valor a um livro interessantíssimo e que se lê de um fôlego e com imenso proveito. Até porque a obra tem um mérito mais, e nada despiciendo: é que ela está longe de ser 'apenas' uma biografia de 15 grandes generais romanos. Pelo contrário, o autor, que apresenta os 15 comandantes por ordem cronológica, tem sempre a preocupação de relacionar intimamente a acção 
desses bravos com o contexto político e com a evolução do próprio exército romano ao longo dos séculos, seja ao nível dos processos de recrutamento, seja no que diz respeito ao armamento ou às tácticas militares utilizadas. Por conseguinte, não só ficamos a conhecer a vida daqueles 15 grandes generais (a sua origem, a sua família, a sua carreira política, o seu percurso militar, as surpresas - tantas vezes nefastas - que o regresso a Roma, mesmo triunfal, lhes reservava, o seu final de vida e até as circunstâncias do seu decesso) como podemos também acompanhar as principais linhas de força da evolução da mais extraordinária máquina de guerra que já existiu à superfície da Terra. Ora, isso torna este trabalho verdadeiramente precioso, não apenas para o leitor comum de biografias históricas, mas também para o estudioso da história militar antiga.

Um último apontamento, para uma breve referência ao capítulo derradeiro, dedicado ao "legado dos generais romanos" (Capítulo 16, pp. 477-488). Trata-se aqui, por um lado, de salientar - sempre na linha 'keeganiana' que vimos apontando - a importância do elemento humano na História. Tal como escreve Goldsworthy, "a personalidade do general é indispensável, ele é a cabeça, ele é todo um exército. Os gauleses não foram conquistados pelas legiões romanas, mas por César" (p. 477). Foi justamente a determinação e impetuosidade de grandes líderes como Marcelo, Fábio Máximo ou Cipião Africano, entre outros, que permitiu a consolidação do "modo romano de fazer a guerra". Um "modo" em que, como também acentuou Goldsworthy durante a palestra de Lisboa, não havia lugar para a piedade nem para o recuo: os Romanos encaravam cada combate como algo de definitivo, não tencionavam voltar as lutar contra os mesmos inimigos (e por isso destruíram Numância e Cartago). Em nenhum rescaldo de derrota em batalha campal (e sofreram muitas) os Romanos deram a guerra por perdida: a sua coragem e tenacidade permitiam sempre reagir e retomar a luta com o objectivo de alcançar a vitória final, mesmo quando tudo parecia perdido (como a seguir ao desastre de Canas, às mãos de Aníbal, em 216 a.C.). Ora, para que isto fosse possível, era essencial dispor de uma liderança forte. Temperados pela luta política, os senadores romanos a quem era entregue um comando militar na condição de cônsules (ou de procônsules, quando havia necessidade de prolongar o imperium) foram os intérpretes dessa 'determinação romana', sustentada por três factores essenciais: 
i) uma base organizativa muitíssimo forte, nunca antes conseguida (falamos de um exército que terá envolvido, em simultâneo, perto de 300.000 homens, controlando durante séculos uma superfície territorial imensa e com um orçamento anual que, sob Diocleciano, deve ter atingido quase 200 milhões de denários); ii) uma notável capacidade para reconhecer nos adversários o que eram os seus pontos fortes e para os importar para o campo de Roma (fossem armas, tácticas ou outra coisa qualquer); iii) uma flexibilidade táctica muito maior do que até aqui se supunha, mas que, graças exactamente aos estudos de Adrian Goldsworthy, tem vindo progressivamente à superfície, mostrando que os legionários não eram meros autómatos inseridos em máquinas militares perfeitamente oleadas e sem independência para iniciativas de carácter individual muitas vezes decisivas, desde que executadas em circunstâncias propícias e em condições adequadas.

Decerto que estes trunfos do exército romano ajudam em muito a explicar o seu tremendo sucesso ao longo de mais de um milénio (estimativa generosa, por considerar apenas o chamado Império Romano do Ocidente), o que constitui um caso único na história da Humanidade. Mas explicam também por que razão líderes dos séculos XVI e XVII como Maurício e Guilherme de Nassau, nos Países Baixos, ou Gustavo Adolfo, na Suécia, "tentavam conscientemente transformar os seus exércitos em forças baseadas na disciplina, organização e sistema táctico das legiões romanas" (p. 482). $\mathrm{O}$ próprio Napoleão Bonaparte conhecia bem a história militar antiga e apreciava deveras Júlio César. Como escreve Goldsworthy, "a sua ordem do dia em Austerlitz - 'Soldados, dirigirei pessoalmente todos os vossos batalhões; manter-me-ei à distância se, com a vossa costumada bravura, levarem a desordem e a confusão às fileiras do inimigo; mas se a vitória for em algum momento incerta, verão o vosso imperador expor-se na linha da frente' - poderia facilmente ter vindo de um general romano" (p. 486). Claro que, depois de Waterloo (1815), as condições no campo de batalha alteraram-se de tal maneira (sistemas de comunicação, capacidade para matar a grande distância, enorme aumento dos campos de batalha) que o modelo romano acabou por se tornar inimitável. No entanto, como sublinha Goldsworthy, os clássicos continuaram sempre presentes na instrução militar e, apesar das reticências de Clausewitz, o estudo da história militar antiga 
teve até certa influência na formação dos oficiais prussianos e, depois, alemães (p. 487).

Sabemos que, a partir do século XIX, o Mundo mudou muito e "uma das maiores mudanças foi a perda de um conhecimento amplo dos clássicos" (p. 488). Ainda assim, as lições dos generais romanos, tantas vezes obrigados a travar "guerras assimétricas contra opositores menos sofisticados do que eles" (ibidem) podem continuar a ser úteis na actualidade. Na sua palestra-apresentação de Lisboa, Adrian Goldsworthy recordou mesmo como a administração norte-americana (preocupada com situações que não é preciso aqui evocar) teve o cuidado de reunir, num fim-de-semana de 2001, em Washington, especialistas de história militar de todas as épocas e de os pôr a discutir estratégia! "Durante boa parte da sua história, o exército romano estava mais bem equipado e, ainda mais importante, muito mais organizado e disciplinado do que os dos seus inimigos. Nos moldes do discurso parlamentar vitoriano, muitas das campanhas romanas foram 'pequenas guerras'. Talvez seja nos modos em que essas operações foram conduzidas que se devam procurar as lições para os dias de hoje, mais do que nas famosas batalhas contra cartagineses e macedónios" (p. 488). Até por isso, este belo livro (que, como salienta Carlos Fabião na sua Nota Prévia, ajuda a cobrir uma lacuna confrangedora no panorama da edição portuguesa de obras sobre o Império Romano) merece ser lido com espírito aberto e prospectivo.

João Gouveia Monteiro (Julho de 2008)

Maria Helena da Cruz Coelho, FORAL DE D. MANUEL I A SANTARÉM. Estudo, Transcrição e Glossário. Santarém: Câmara Municipal de Santarém, 2007.

"Uma comunidade que ignora a sua memória construída ao longo de séculos, ou mesmo de décadas, não tem condições para avaliar as energias, os desafios, os meios de que dispõe para planear as expectativas de futuro incorporadas nos projectos com que é esperado" (Francisco Moita Flores). Convicto de que sem passado não há futuro viável, o Senhor Presidente 